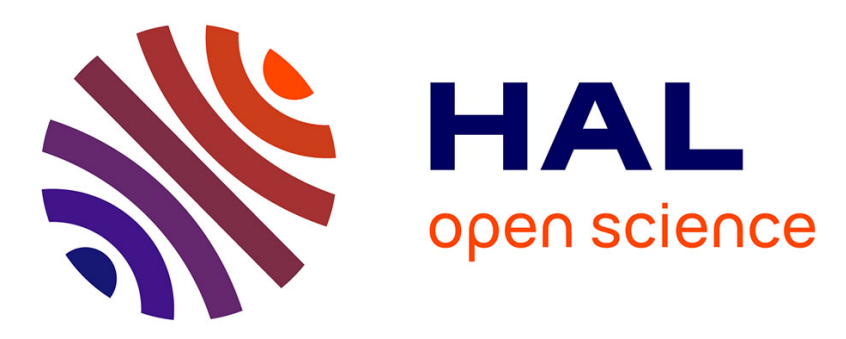

\title{
Looking into each other's eyes makes it better: eye-to-eye contact enhances sexual interactions in wild geladas
}

Anna Zanoli, Marco Gamba, Alban Lemasson, Elisabetta Palagi, Ivan Norscia

\section{- To cite this version:}

Anna Zanoli, Marco Gamba, Alban Lemasson, Elisabetta Palagi, Ivan Norscia. Looking into each other's eyes makes it better: eye-to-eye contact enhances sexual interactions in wild geladas. Animal Behaviour, 2021, 177, pp.269-276. 10.1016/j.anbehav.2021.05.011 . hal-03264410

HAL Id: hal-03264410

https://hal-univ-rennes1.archives-ouvertes.fr/hal-03264410

Submitted on 29 Jun 2021

HAL is a multi-disciplinary open access archive for the deposit and dissemination of scientific research documents, whether they are published or not. The documents may come from teaching and research institutions in France or abroad, or from public or private research centers.
L'archive ouverte pluridisciplinaire HAL, est destinée au dépôt et à la diffusion de documents scientifiques de niveau recherche, publiés ou non, émanant des établissements d'enseignement et de recherche français ou étrangers, des laboratoires publics ou privés. 
1 Looking into each other's eyes makes it better: Eye-to-Eye Contact enhances sexual interactions in geladas

Anna Zanoli ${ }^{a}$, Marco Gamba ${ }^{a}$, Alban Lemasson ${ }^{b}$, Elisabetta Palagi ${ }^{c, d, *}$, \& Ivan Norscia ${ }^{a, c, *}$ 5

${ }^{a}$ University of Turin, Department of Life Sciences and Systems Biology, Italy

7 buniversity of Rennes, University of Normandie, CNRS, EthoS (Éthologie animale et humaine), 8 France

$9 \quad{ }^{\mathrm{c}}$ Natural History Museum, University of Pisa, Calci, Italy

10 dUnit of Ethology, Department of Biology, University of Pisa, Italy

12 *Corresponding authors:

13 Ivan Norscia:

14 E-mail: ivan.norscia@unito.it

15 Postal Address: University of Turin, Department of Life Sciences and Systems Biology, Via 16 Accademia Albertina 13, 10123 Torino (Italy)

17 Telephone: +390116704547

19 Elisabetta Palagi:

20 E-mail: elisabetta.palagi@unipi.it

21 Postal Address: Unit of Ethology, Department of Biology, University of Pisa, Via A. Volta 6, 56126

22 Pisa (Italy)

23

24

25

26

27 
In human and non-human primates Eye-to-Eye Contact (EEC), a face-to-face communication component, can promote emotional/attentional engagement, and prolong affiliative interactions. Due to its direct impact on fitness, the reproductive context is perhaps the most critical context for investigating EEC's importance. However, the presence of this phenomenon around mating and its functions in primates is still understudied. In this work, we investigated whether EEC was present during copulations and influenced the copula duration and post-copulation grooming occurrence in the wild gelada (Theropithecus gelada), an Old World monkey species. We found that the previous presence of the male 'look-at' triggered the female 'look-at'. Moreover, copulations were most likely to last longer in the presence of EEC. In addition, the occurrence of post-copulation grooming between partners - most frequently initiated by females - increased when copulations included EEC. Females' engagement in EEC with the male may be a form of continuation of female pre-copulatory proceptivity and facilitate males' copulatory activity. EEC by prolonging sexual contacts, may also increase the chances of ejaculation. By grooming their partners after mating, female geladas may attempt to reduce male arousal and prolong the social interaction with them, possibly strengthening their social bond. These results provide the first quantitative evidence that EEC is an effective mechanism for prolonging mating interactions and enhancing post-mating affiliation in a Papionini species. On a broader perspective, the presence of EEC in an Old-World monkey species suggests that EEC may have been favoured by natural selection to promote reproductive advantages during human evolution.

KEYWORDS: Eye-to-Eye Contact; facial communication; mutual gaze; reciprocal looking; sexual behaviour; social bonding; Theropithecus gelada; visual communication 
In evolutionary terms, the measure of an individual's success is the amount of its genes present in subsequent generations (Smith \& Maynard-Smith, 1978). Being the critical point of an individual's existence, reproduction is the central theme around which all other aspects of biology revolve (Dunbar, 2014). Among the different forms of reproduction, sexual reproduction is the most common in nature, and it depends on effective communication between senders and receivers (Bell, 1982). Courtship and mating involve the production of sexual signals that transmit crucial information about the senders' identity, quality, social status, and motivation (Bradbury \& Vehrencamp, 1998). Depending on the species, the exchange of information in the reproductive context can occur via different sensory modalities (Partan \& Marler, 1999; 2005). Although hearing and/or smell can be crucial in primates, vision is pivotal for communication, especially in anthropoids. For example, their relatively large, forward-facing eyes give rise to binocular eyesight fields, enabling stereoscopic vision (Ravosa \& Savakova, 2004; Fleagle, 2013). Despite the importance of visual signals in primates (Higham et al., 2011; 2012), eye-gaze behaviour in the reproductive context has not received much attention so far (Dixson, 2012; Liebal, Waller, Slocombe, \& Burrows, 2014).

In anthropoids, face-to-face communication is important in regulating social interactions such as competition, affiliation, and socio-sexual contacts (Gothard, Erickson, \& Amaral, 2004; Parr, Waller, Vick, \& Bard, 2007; Micheletta, Whitehouse, Parr, \& Waller, 2015; Annicchiarico, Bertini, Cordoni, \& Palagi, 2020; for a review see: Waller \& Micheletta, 2013). In human and other non-human primates, specific forms of face-to-face communication such as rapid facial mimicry and yawn contagion are associated with enhanced affiliative behaviour and social bonding (Mancini, Ferrari, \& Palagi, 2013a; Norscia \& Palagi, 2011).

Eye-to-Eye Contact (EEC) is a crucial component of face-to-face communication (Kret, Fischer, \& De Dreu, 2015; Schino \& Sciarretta, 2016). The Cooperative Eye Hypothesis (CEH) predicts that EEC in humans has evolved to maintain cooperative behaviours (Tomasello, Hare, Lehmann, \& Call, 2007). In non-human primates, EEC can also be an effective way to convey essential information about the subjects' motivation when they engage in social interactions (Wrangham, 1993; Kobayashi 
\& Hashiya, 2011). In this respect, EEC may be a means to promote emotional/attentional engagement, thus prolonging affiliative interactions (Cordell \& McGahan, 2004; Prochazkova \& Kret, 2017; Annicchiarico et al., 2020).

EEC can become particularly critical when reproduction is at stake (Dixson, 2012). In many primate species, spanning monkeys and apes, females can turn to look back and establish eye-to-eye contact with males during copulation, as a possible continuation of pre-copulatory, eye-contact proceptivity (Dixson, 2012; Chevalier-Skolnikoff, 1975). According to previous reports, this visual contact can facilitate male's copulatory activity, enhance its arousal, and prolong the sexual contact, thus improving ejaculation chances (Dixson, 2012; Palagi, Bertini, Annicchiarico, \& Cordoni, 2020a). Therefore, sex - due to its direct impact on fitness - is perhaps the most critical context to evaluate the importance of EEC (Dixson, 2012; Palagi et al., 2020a). However, despite its importance, facial communication around mating - that includes EEC - and its implications for social bonding in primates remains understudied (Dixson, 2012).

Here, we focused on Theropithecus gelada (Hill, 1970) to understand whether EEC was present during copulations and, if so, how it influenced mating interactions. Geladas possess a rich repertoire of facial expressions (Dunbar \& Dunbar, 1975) that they use to communicate in different contexts: playful context (play face - full play face: Palagi \& Mancini, 2011; Mancini et al., 2013a; Mancini, Ferrari, \& Palagi, 2013b); affiliative context (yawns: Leone, Ferrari, \& Palagi, 2014; Palagi, Leone, Mancini, \& Ferrari, 2009; lip-smacking: Gustison, le Roux, \& Bergman, 2012); and agonistic context (yawns: Leone et al., 2014; lip-flip: Lazow \& Bergman, 2020). In the mating context both male and female geladas can emit different vocalizations around copulation (Aich, Moos-Heilen, \& Zimmermann, 1990; Gustison et al., 2012; Gustison \& Bergman, 2017; Gustison, Johnson, Beehner, \& Bergman, 2019), but little it is known about the eye-gaze behaviour in this context.

To fill this gap, this study aimed at testing the following hypotheses:

(1) If visual communication has a role in managing the mating interaction in geladas, we expect that males and females seek EEC with the partner. 
114 (2) If EEC contributes to increasing the probability of the ongoing copula's success, we expect the

115 longest copulas to be characterized by the presence of EEC.

116 (3) If EEC enhances post-mating affiliation probability, we expect that grooming (the primary form 117 of affiliation in primates; Dunbar, 1991) between mates is widespread after copulations including 118 EEC.

METHODS

Study Subjects and Data Collection

123 We conducted this research on the Kundi highland (North Shewa Zone, Amhara Region, Ethiopia N940.402’ E3945.060’), regularly frequented by 18 One-Male Units (OMUs) of geladas. Data were collected from January to May 2019, and from December 2019 to February 2020. From two to four observers (A.Z. and three field assistants) observed the visible OMUs every day from 0930 hours to 1700 hours, for a total of 658 hours of observation. By using the all-occurrences sampling method (Altmann 1974), all copulations (including possible post-copulation grooming between mates) performed by the visible animals were audio- and video-recorded. Copulations were easily predictable thanks to clearly detectable visual and acoustic sexual invitations (present-rear, genital 131 inspection, and female pre-copulation calls; Dunbar \& Dunbar, 1975). Hence, the observers were able 132 to anticipate impending copulations and to record each mating before it began. We made video 133 recordings by using HC-V180 Full HD Panasonic video cameras (optical zoom 50×). We recorded 134 sounds using Zoom H5, OLYMPUS-LS100 and Marantz PMD661 solid-state digital audio recorders 135 built up with Sennheiser ME64 and Sennheiser ME66 microphones with a sampling rate of 96kHz 136 (16-bit depth). We recorded a total of 443 mating events, but, for this study, we could only use a 137 subset of 244 copulations performed by 145 dyads from 18 One-Male units (18 alpha males and 142 138 adult females). The high-quality resolution (1920x1080 Pixel) and the optical zoom (50×) allowed to 139 obtain optimal frames of faces and eyes of the mating subjects. Nevertheless, we had to exclude from 
the complete dataset all the cases $(N=199)$ in which it was impossible to see the interacting

141 individuals' eyes due to distance, limited visibility (e.g., foggy weather), and/or animal position.

Operational Definitions and Data Processing

144 The copulation videos were analysed frame-by-frame via the freeware VideoLAN Client 3.0.11.1 145 (2020; with the extension Jump to Time) whereas the audio-recordings were analysed by using Praat 146 6.0.56 (Boersma \& Weenink, 2008). Copulation started when the genital areas of the male and the female entered in contact and ended when one of them spontaneously interrupted the contact. We assigned each copulation to one of the conditions described here below. We defined the condition "no-look" when: (a.1) the male turned its face (and gaze) away from the female, (a.2) the male oriented its face frontally without lowering the head, and (b.1) the female did not turn its head back,

151 (b.2) the female turned its head, but its gaze was not directed at the male. In the condition "male lookat" (a) the male lowered its head and had its gaze directed towards the female, but (b.1) the female did not turn its head back, or (b.2) the female turned its head, but its gaze was not directed at the male. We defined the condition "female look-at" when (a) the female turned its head back and had its gaze directed towards the male, but (b.1) the male turned its face (and gaze) away from the female, (b.2) the male oriented its face frontally without lowering the head. We defined the condition "Eye-to-Eye Contact" (EEC) when the look-at was reciprocated, with male and female looking into each other's eyes. So, the look-at conditions could become an EEC interaction only if one subject looked its partner back. The conditions assigned to each copulatory event were based on the presence/absence 160 of look-at or EEC, not on the gaze duration. Examples of each condition are shown in Figure 1.

161 Both "male look-at" and "female look-at" conditions started when one of the mating subjects looked 162 at the other and ended when one of the subjects interrupted the visual contact. EEC conditions started 163 when both sexes looked into each other eyes and ended when one of the subjects interrupted the visual contact. If a copulation included both look-at and EEC, such copulation fell into the EEC condition. 
165 This methodology avoided data pseudo-replication. Since the mean duration of a copulatory event

166 was $10.18( \pm$ SD 4.15) seconds, we defined as "post-copulation grooming" each

167 grooming session occurring within 10 s of the end of the copulation.

168 Following Roberts, Lu, Bergman, \& Beehner (2017), we classified the female status as "oestrus" and 169 "non-oestrus" based on the chest vesicle coverage and turgidity, the chest colour, and the presence of 170 paracallosal vesicles.

171 A.Z. analysed all the videos. Twenty-four randomly selected copulation events ( $10 \%$ of the total 172 sample) were assigned to another observer, expert in gelada behaviour and unaware of the study's 173 aim, to check for inter-observer agreement and reliability over scoring. For each category in which 174 we divided our sample Cohen's kappa values were: no-look $=1$ male look-at $=0.95$, female look-at $175=0.90$, and $\mathrm{EEC}=1$.

176 From each copulation video we extracted the following data: (1) identity of the mating dyad, (2) 177 copula duration, (3) the second when look-at and EEC occurred, (4) occurrence of post-copulatory 178 grooming, and (5) female oestrus status. We used the audio recordings to extract (1) presence/absence 179 of male copulation calls (Aich et al., 1990), (2) the second when each subject started the emission of 180 copulation calls, and (3) presence/absence of male post-copulation call sequences. We extracted a 181 behavioural string for each copulatory event, including the temporal sequence of all behaviours and vocalizations.

\section{Statistical Analysis}

185 Preliminarily, we conducted a sequential analysis to evaluate the temporal association of the target 186 behavioural patterns and vocalizations (hereafter "items") during and after copulatory events. We 187 created a string for each copulation, including the items separated by a break symbol. The resulting 188 string represented the ordered concatenation of items as they occurred during copulation. Using the 189 software Behatrix 0.9.11 (Friard, \& Gamba, 2020), we generated the flow diagram with the transitions 190 from one item to the next, with the percentage values of transition relative occurrences. Then, we ran 
a permutation test based on observed counts of the behavioural transitions ("Run random permutation test" Behatrix-function). We permuted the strings 10000 times (allowing us to achieve an accuracy of 0.001 of the probability values) and we obtained $P$-values for each behavioural transition. The sequential analysis showed that the male look-at occurred more frequently before the female look-at. For this reason, we ran a Generalized Linear Mixed Model (GLMM; "Ime4" package: Bates, Mächler, Bolker, \& Walker, 2015) in R (R Core Team, 2020; version 4.0.2) to verify which variables could affect the occurrence of the female look-at during copulations. This model included the female look-at (presence/absence) as a binomial response variable. The occurrence of male look-at (presence /absence), male copulation calls (presence/absence), and the female oestrus status (oestrus/nonoestrus) were entered as binomial fixed factors, whereas the dyad identity was entered as a random 201 factor.

We ran a second model to investigate whether the presence of EEC affected the copula duration (LMM, family = "gaussian"). The log-transformed copula duration (in seconds) was the response variable, whereas EEC (presence/absence) and male look-at (presence/absence) were the fixed factors, and the dyad identity was the random factor. For this model, we verified the normal distribution and homogeneity of the residuals by looking at the qq-plot and plotting the residuals against the fitted values (Estienne, Mundry, Kühl, \& Boesch, 2016).

208 Finally, to verify whether EEC's presence influenced the occurrence of post-copulation grooming, we 209 ran a third GLMM. The occurrence of post-copulation grooming (presence/absence) was the binomial 210 response variable. EEC (presence/absence) and male post-copulation call sequence

211 (presence/absence), and the copula duration were the fixed factors, whereas the dyad identity was the 212 random factor.

213 For all models, we computed multicollinearity with generalised variance inflation factors (GVIF; Fox 214 \& Monette, 1992) in R (“vif” function; Fox \& Weisberg, 2011). The GVIF revealed no collinearity 215 between fixed factors ( $<1.02$ in all cases). To test the significance of the models, we compared each 216 full model with a null model including only the random factor (Forstmeier \& Schielzeth, 2011), using 
217 a likelihood ratio test (Anova with the "Chisq" test argument; Dobson, 2002). Then, we estimated p-

218 values for each predictor based on likelihood ratio tests between the full model and the respective 219 null model (R-function “drop1”; Barr, Levy, Scheepers, \& Tily, 2013).

\section{Ethical Note}

This is a non-invasive research compliant with the ASAB/ABS Guidelines for the Use of Animals in Research, the current Ethiopian Italian and French law and University regulations. Thus, no permit from the Bio-Ethical Committee was needed.

\section{RESULTS}

\section{Behavioural Transitions During and After Copulation}

229 The sequential analysis on the behaviours/vocalizations revealed that, during copulations, both males and females emitted copulation calls before looking at each other (transition male copulation calls male look-at : percentage of occurrence $=9.22 \% ; P=0.040$; transition male copulation calls $\square$ female look-at: percentage of occurrence $=14.89 \% ; P=0.007$; transition female copulation calls $\square$ male look-at: percentage of occurrence $=13.63 \% ; P=0.008$; transition female copulation calls $\square$ female

234 look-at: percentage of occurrence $=24.24 \% ; P<0.001)$. In addition, most frequently the male was 235 the first to look at the female (transition male look-at $\square$ female look-at: percentage of occurrence $236=43.75 \% ; P<0.001)$. Finally, during copulations EEC was followed by grooming (started by the 237 female $)$ in the $70.58 \%$ of the cases $(P<0.001)$. A flow diagram with the significant behavioural 238 transitions is reported in Figure 2a.

EEC Presence and Effects During and After Copulation

241 When investigating which variables affected the female look-at occurrence, we found that the full model significantly differed from the null model $(\chi 2=27.519, d f=5, P<0.001$; Table 1$)$. The previous 
presence of male look-at was associated with an increased likelihood of female-look at (Figure 1b),

244 whereas the main effect of male copulation calls did not reach statistical significance. Likewise, the 245 female oestrus status did not affect the occurrence of female look-at.

246 The full model that we built to check whether EEC affected the copula duration significantly differed 247 from the null model $(\chi 2=7.211, d f=5, P=0.027$; Table 2$)$. We found that copulations in which EEC 248 was present lasted significantly more (mean $[\mathrm{s}] \pm \mathrm{SD}=13.203 \pm 4.659)$ than copulations in which 249 EEC was absent (mean $[\mathrm{s}] \pm \mathrm{SD}=8.390 \pm 2.624)$ (Figure 1c).

250 Finally, we built a model to investigate whether EEC during copulations influenced the occurrence 251 of post-copulation grooming. The full model significantly differed from the null model $(\chi 2=9.206, d f=5, P=0.026$; Table 3$)$. We found that EEC's presence during copulations was associated with an increased likelihood of post-copulation grooming (Figure 1d). In contrast, male post-copulation call sequences and the copula duration did not have a significant main effect on the target variable.

\section{DISCUSSION}

This study investigated whether Eye-to-Eye Contact (EEC) was present during copulation and affected copula duration and post-copulation grooming in wild geladas. We found that during copulations, female look-at was influenced by the previous presence of male look-at but not by the previous emission of male copulation calls (Figure 2a, $2 \mathrm{~b}$ - in line with Prediction 1). Moreover, copulations were most likely to last longer when EEC was present (Figure $2 \mathrm{c}-$ in line with Prediction 2), but not when only male look-at occurred. Finally, the probability of post-copulation grooming 264 between partners increased (with grooming most likely started by females) when copulations included 265 EEC (Figure 2a, 2d - in agreement with Prediction 3). These results provide the first quantitative evidence of EEC's presence during copulations in geladas and allow inferences on its potential functions in favouring positive social interactions. As predicted, partners looked at each other, with females being most likely to look at the male after being looked 
by the male independently from the presence of male copulation calls. Although geladas possess an 270 elaborate vocal repertoire used in the mating context (Aich et al., 1990; Gustison et al., 2012; Gustison 271 \& Bergman, 2017; Gustison et al., 2019), in this case, male copulation calls do not seem to be the main trigger of the visual contact (Table 1; Figure 2b). This result suggests that the female look-at was not a simple reaction to male copulation calls, but that the females probably sought for EEC with males. Previous studies showed that in all major radiations of anthropoid primates, including New World monkeys (e.g. Callimico goeldii: Heltne, Wojcik, \& Pook, 1981; Callithrix jacchus: Kendrick \& Dixson, 1984; Leontopithecus rosalia: Kleiman, Hoage, \& Green, 1988; Brachyteles arachnoides: Milton, 1985), Old World monkeys (e.g. Macaca spp: Hinde \& Rowell, 1962; Zumpe \& Michael, 1968; Dixson, 1977; Wolfe, 1984; Slob \& Nieuwenhuijsen, 1980; Slob et al., 1986; Chevalier-

Skolnikoff, 1975; in Lophocebus albigena: Wallis, 1983; Papio ursinus: Saayman, 280 1970; Miopithecus talapoin: Dixson, Scruton, \& Herbert, 1975) and apes (Pan paniscus: Tutin \& 281 McGinnis, 1981; Palagi et al., 2020a; Pan troglodytes: Goodall, 1986; Gorilla beringei beringei: Harcourt, 1981), EEC between partners possibly occurred also during dorso-ventral sexual interactions. As reported for other primate species, gelada females may seek the males' eye-contact to assess males' intent and communicate their engagement. In this respect, females seeking eye contact can, therefore, be interpreted as a form of a possible continuation of pre-copulatory, eyecontact proceptivity (Dixson, 2012).

EEC was present during copulations and associated with more prolonged sexual interactions (Figure $2 \mathrm{c}$ - Prediction 2 supported). Besides, we found that the male look-at's presence did not per se affect the copula duration (Table 2). This result allowed us to exclude the possibility that copulation lasted 290 longer because males were generally more "attentive". In a general perspective, this result is in line 291 with previous findings on the possible function of EEC in prolonging social interactions in humans and apes under different contexts (Homo sapiens: Cordell \& McGahan, 2004; Prochazkova \& Kret, 2017; Pan paniscus: Annicchiarico et al., 2020). More specifically, our findings support the previous, 
described that in bonobos, the success of sexual interactions, estimated by their duration, could be 296 associated with maintaining mutual gaze during sexual contacts. More recently, Palagi et al. (2020a) reported that the presence of rapid facial mimicry (a facial mirror response occurring within a second after the perception of other facial expressions; Mancini et al., 2013a; Palagi, Celeghin, Tamietto, Winkielman, \& Norscia, 2020b) increased the duration of bonobo hetero-sexual contacts. Female look-at during mating may trigger male pelvic thrusting, which ends with ejaculation (Brachyteles arachnoides; Milton, 1985). Thus, we can suppose that also in geladas EEC may facilitate the copulatory activity of males, enhance their sexual arousal and, by prolonging the sexual contact, increase ejaculation chances.

Finally, we found that EEC's presence was associated with an increased occurrence of post-copulation grooming, especially started by females (Figure 2a, 2d). The duration of copulas (a possible proxy of the copulation's success; Milton, 1985) and male post-copulation call sequences did not significantly affect the subsequent occurrence of grooming. Hence, it is unlikely that these two factors were the primary triggers of the post-copulation grooming increase (Table 3). However,

310 link between EEC and ejaculation. Our result supports our third prediction and can be discussed on 311 two levels. In the short term, if EEC's presence during copulations increased the levels of male 312 arousal, females - by grooming the partner - may attempt to reduce such arousal to favour affiliative 313 interactions. Previous findings reported that grooming is effective in reducing arousal-related anxiety 314 in non-human primates, from lemurs to apes (e.g., Lemur catta: Sclafani, Norscia, Antonacci, \& 315 Palagi, 2012; Macaca fascicularis: Schino, Scucchi, Maestripieri, \& Turillazzi, 1988; Pan paniscus: 316 Palagi \& Norscia, 2013; Pan troglodytes: De Waal \& van Roosmalen, 1979; for a review see: Dunbar, 317 2010). Similarly, in humans, mutual-grooming may serve to reduce relationship-related anxiety and 318 favour bonding (Nelson \& Geher, 2007).

319 In the longer run, gelada females may try to prolong the social interaction with males and possibly 320 reinforce their social bond with them. In primates, grooming is the predominant form of affiliation 
used to establish, maintain and strengthen social bonds (Dunbar, 1991). Moreover, in previous studies on human and non-human primates, EEC has been described as an effective mechanism that has evolved to maintain cooperative behaviours and prolong affiliative interactions by promoting emotional/attentional engagement (Tomasello et al., 2007; Cordell \& McGahan, 2004; Prochazkova $\&$ Kret, 2017; Annicchiarico et al., 2020). This explanation may be especially valid in the light of the characteristics of geladas. In this species, females can benefit from male protection, especially in relation to reproduction, considering that high levels of infanticides have been observed in case of takeover attempts (Mori, Shimizu, \& Hayashi, 2003; Beehner \& Bergman, 2008; Roberts, Lu, Bergman, \& Beehner, 2012; Pallante, Stanyon, \& Palagi, 2016). By prolonging the social interaction with males by grooming them after mating, females may reinforce social bonding and increase male 331 protection.

332 The impossibility of evaluating the quality of the relationship between the mating partners may be a 333 limitation of this study. This factor could affect the gaze behaviour during copulations and the 334 grooming rate between the partners and could lead to more comprehensive results. Although long335 term studies are necessary to assess EEC's function in strengthening social bonding between male 336 and female geladas, we provided reliable support that EEC represents an effective mechanism to 337 prolong mating interactions (possibly increasing chances of success) and enhance post-copula 338 affiliation in a species of Papionini. More generally, this study confirms that visual communication 339 can function as an aid to reproduction (Liebal et al., 2014). Finally, by focusing on an Old-World 340 monkey species (which separated from the human lineage around 18-22 million years ago; Pozzi et 341 al., 2014), this study suggests that EEC may have long been favoured by natural selection to promote 342 reproductive advantages over the course of human evolution. 


\section{REFERENCES}

Aich, H., Moos-Heilen, R., \& Zimmermann, E. (1990). Vocalizations of adult gelada baboons

(Theropithecus gelada): acoustic structure and behavioural context. Folia primatologica, 55(3-4), 109-132. https://doi.org/10.1159/000156508.

Altmann, J. (1974). Observational study of behavior: sampling methods. Behaviour 49, $227-267$. https://doi.org/10.1163/156853974X00534.

Annicchiarico, G., Bertini, M., Cordoni, G., \& Palagi, E. (2020). Look at me while having sex! Eye-to-eye contact affects homosexual behaviour in bonobo females. Behaviour, 1(aop), 1-22. https://doi.org/10.1163/1568539X-bja10034.

Barr, D. J., Levy, R., Scheepers, C., \& Tily, H. J. (2013). Random effects structure for confirmatory hypothesis testing: keep it maximal. Journal of Memory and Language, 68, 255-278. https://doi.org/10.1016/j.jml.2012.11.001.

Bates, D., Mächler, M., Bolker, B., \& Walker, S. (2015). Fitting Linear Mixed- Effects Models using lme4. Journal of Statistical Software, 67, 1-48. https://doi.org/10.18637/jss.v067.i01.

Beehner, J. C., \& Bergman, T. J. (2008). Infant mortality following male takeovers in wild geladas. American Journal of Primatology: Official Journal of the American Society of Primatologists, 70(12), 1152-1159. https://doi.org/10.1002/ajp.20614.

Bell, G. (1987). Two theories of sex and variation. In The evolution of sex and its consequences (pp. 117-134). Birkhäuser, Basel. https://doi.org/10.1007/978-3-0348-6273-8 5.

Boersma, P., \& Weenink, D. (2008). Praat: Doing Phonetics by Computer (Computer Program). Retrieved from https://www.fon.hum.uva.nl/praat/. Accessed December 22, 2020 
368 Bradbury, J. W., \& Vehrencamp, S. L. (1998). Principles of animal communication. Sinauer

369 Associates.

370 Brunson, J. C., Read, Q. D. (2020). ggalluvial: Alluvial Plots in 'ggplot2'. R package version 0.12.3.

371 Retrieved from http://corybrunson.github.io/ggalluvial/. Accessed December 28, 2020

372 Chevalier-Skolnikoff, S. (1975). Heterosexual copulatory patterns in stumptail macaques (Macaca

373 arctoides) and in other macaque species. Archives of sexual behavior, 4(2), 199-220.

374 https://doi.org/10.1007/BF01541083.

375 Cordell, D. M., \& McGahan, J. R. (2004). Mutual Gaze Duration as a Function of Length of

376 Conversation in Male-Female Dyads. Psychological reports, 94(1), 109-114.

377 https://doi.org/10.2466\%2Fpr0.94.1.109-114.

378 De Waal, F. B., \& van Roosmalen, A. (1979). Reconciliation and consolation among

379 chimpanzees. Behavioral Ecology and Sociobiology, 5(1), 55-66.

380 https://doi.org/10.1007/BF00302695.

381 Dixson, A. F. (1977). Observations on the displays, menstrual cycles and sexual behaviour of the

382 "Black ape" of Celebes (Macaca nigra). Journal of Zoology, 182(1), 63-84.

383 https://doi.org/10.1111/j.1469-7998.1977.tb04141.x.

384 Dixson, A. F., Scruton, D. M., \& Herbert, J. (1975). Behaviour of the talapoin monkey

385 (Miopithecus talapoin) studied in groups, in the laboratory. Journal of Zoology, 176(2), 177-210.

386 https://doi.org/10.1111/j.1469-7998.1975.tb03192.x.

387 Dixson, A. F., (2012). Primate Sexuality: Comparative Studies of the Prosimians, Monkeys, Apes, 388 and Humans. Oxford University Press. 
389 Dobson, A. J. (2002). An Introduction to Generalized Linear Models. (2nd ed.). Boca Raton, FL:

390 Chapman and Hall/CRC Press.

391 Dunbar, R. I. (1991). Functional significance of social grooming in primates. Folia

392 primatologica, 57(3), 121-131. https://doi.org/10.1159/000156574.

393 Dunbar, R. I. (2010). The social role of touch in humans and primates: behavioural function and

394 neurobiological mechanisms. Neuroscience \& Biobehavioral Reviews, 34(2), 260-268.

395 https://doi.org/10.1016/j.neubiorev.2008.07.001.

396 Dunbar, R. I. M. (2014). Reproductive decisions: an economic analysis of gelada baboon social 397 strategies. Princeton, New Jersey: Princeton University Press.

398 Dunbar, R. I. M. \& Dunbar, P. (1975). Social dynamics of gelada baboons. In H. Kuhn, W. P. 399 Luckett, C. R. Noback, A. H. Schultz, D. Starck \& F. S. Szalay (Eds.) Contributions to Primatology 400 (pp. 1-157). Basel: S. Karger.

401 Estienne, V., Mundry, R., Kühl, H. S., \& Boesch, C. (2017). Exploitation of underground bee nests 402 by three sympatric consumers in Loango National Park, Gabon. Biotropica, 49(1), 101-109. $403 \quad$ https://doi.org/10.1111/btp.12354.

404 Fleagle, J. G. (2013). Primate adaptation and evolution. Academic press.

405 Forstmeier, W., \& Schielzeth, H. (2011). Cryptic multiple hypotheses testing in linear models: 406 overestimated effect sizes and the winner's curse. Behavioral Ecology and Sociobiology, 65, 47-55. 407 https://doi.org/10.1007/s00265-010-1038-5.

408 Fox, J., \& Monette, G. (1992). Generalized collinearity diagnostics. Journal of the American 409 Statistical Association, 87(417), 178-183. https://doi.org/10.1080/01621459.1992.10475190. 
410 Fox, J., \& Weisberg, S. (2011). An R Companion to Applied Regression. (2nd ed). Thousand Oaks, 411 CA: SAGE Publications, Inc.

412 Friard, O., Gamba, M., (2020). Behatrix: Behavioral sequences analysis with permutations test. 413 Retrieved from http://www.boris.unito.it/pages/behatrix. Accessed January 04, 2021

414 Goodall, J. (1986). The chimpanzees of Gombe: Patterns of behavior. Cambridge Mass.

415 Gothard, K. M., Erickson, C. A., \& Amaral, D. G. (2004). How do rhesus monkeys (Macaca 416 mulatta) scan faces in a visual paired comparison task?. Animal cognition, 7(1), 25-36.

417 https://doi.org/10.1007/s10071-003-0179-6.

418 Gustison, M. L., \& Bergman, T. J. (2017). Divergent acoustic properties of gelada and baboon 419 vocalizations and their implications for the evolution of human speech. Journal of Language 420 Evolution, 2(1), 20-36. https://doi.org/10.1093/jole/lzx015.

421 Gustison, M. L., le Roux, A., \& Bergman, T. J. (2012). Derived vocalizations of geladas 422 (Theropithecus gelada) and the evolution of vocal complexity in primates. Philosophical 423 Transactions of the Royal Society B: Biological Sciences, 367(1597), 1847-1859.

424 https://doi.org/10.1098/rstb.2011.0218.

425 Gustison, M. L., Johnson, E. T., Beehner, J. C., \& Bergman, T. J. (2019). The social functions of 426 complex vocal sequences in wild geladas. Behavioral Ecology and Sociobiology, 73(1), 14.

427 https://doi.org/10.1007/s00265-018-2612-5.

428 Harcourt, A. H. (1981). Gorilla reproduction in the wild. Reproductive biology of the great apes.

429 Heltne, P. G., Wojcik, J. F., \& Pook, A. G. (1981). Goeldi's monkey, genus Callimico. In Ecology 430 and Behaviour of Neotropical Primates (Vol. I, pp. 169-221). Rio de Janeiro: Academia Brasiliera 431 de Ciências 
432 Higham, J. P., Hughes, K. D., Brent, L. J., Dubuc, C., Engelhardt, A., Heistermann, M., ... \& 433 Stevens, M. (2011). Familiarity affects the assessment of female facial signals of fertility by free434 ranging male rhesus macaques. Proceedings of the Royal Society B: Biological 435 Sciences, 278(1723), 3452-3458. https://doi.org/10.1098/rspb.2011.0052.

436 Higham, J. P., Heistermann, M., Saggau, C., Agil, M., Perwitasari-Farajallah, D., \& Engelhardt, A. 437 (2012). Sexual signalling in female crested macaques and the evolution of primate fertility 438 signals. BMC evolutionary biology, 12(1), 1-10. https://doi.org/10.1186/1471-2148-12-89.

439 Hill, W. C. O. (1970). Primates, comparative anatomy and taxonomy. Vol. VIII. Cynopithecinae, 440 Papio, Mandrillus, Theropithecus.

441 Hinde, R. A., \& Rowell, T. E. (1962, January). Communication by postures and facial expressions 442 in the rhesus monkey (Macaca mulatta). In Proceedings of the Zoological Society of London(Vol. 443 138, No. 1, pp. 1-21). Oxford, UK: Blackwell Publishing Ltd. https://doi.org/10.1111/j.1469$444 \quad$ 7998.1962.tb05684.x.

445 Kendrick, K. M., \& Dixson, A. F. (1984). A quantitative description of copulatory and associated 446 behaviors of captive marmosets (Callithrix jacchus). International journal of primatology, 5(3), 447 199-212. https://doi.org/10.1007/BF02735757.

448 Kleiman, D. G., Hoage, R. J., \& Green, K. M. I., (1988). Description of species. In Ecology and 449 Behavior of Neotropical Primates (pp. 2-299).

450 Kret, M. E., Fischer, A. H., \& De Dreu, C. K. (2015). Pupil mimicry correlates with trust in in451 group partners with dilating pupils. Psychological science, 26(9), 1401-1410.

452 https://doi.org/10.1177\%2F0956797615588306. 
453 Kobayashi, H., \& Hashiya, K. (2011). The gaze that grooms: contribution of social factors to the 454 evolution of primate eye morphology. Evolution and Human Behavior, 32(3), 157-165.

455 https://doi.org/10.1016/j.evolhumbehav.2010.08.003.

456 Lazow, S. P., \& Bergman, T. J. (2020). The structural and motivational role of the unique lip-flip 457 movement in the gelada (Theropithecus gelada) facial display repertoire. American Journal of 458 Physical Anthropology, 172(2), 280-290. https://doi.org/10.1002/ajpa.24031.

459 Leone, A., Ferrari, P. F., \& Palagi, E. (2014). Different yawns, different functions? Testing social 460 hypotheses on spontaneous yawning in Theropithecus gelada. Scientific reports, 4, 4010.

$461 \quad$ https://doi.org/10.1038/srep04010.

462 Liebal, K., Waller, B. M., Slocombe, K. E., \& Burrows, A. M. (2014). Primate communication: a 463 multimodal approach. Cambridge University Press.

464 Mancini, G., Ferrari, P. F., \& Palagi, E. (2013a). Rapid facial mimicry in geladas. Scientific 465 reports, 3(1), 1-6. https://doi.org/10.1038/srep01527.

466 Mancini, G., Ferrari, P. F., \& Palagi, E. (2013b). In play we trust. Rapid facial mimicry predicts the 467 duration of playful interactions in geladas. PloS one, 8(6), e66481.

468 https://doi.org/10.1371/journal.pone.0066481.

469 Micheletta, J., Whitehouse, J., Parr, L. A., \& Waller, B. M. (2015). Facial expression recognition in 470 crested macaques (Macaca nigra). Animal Cognition, 18(4), 985-990.

471 https://doi.org/10.1007/s10071-015-0867-z.

472 Milton, K. (1985). Mating patterns of woolly spider monkeys, Brachyteles arachnoides:

473 implications for female choice. Behavioral Ecology and Sociobiology, 17(1), 53-59.

474 https://doi.org/10.1007/BF00299429. 
475

Mori, T., Shimizu, K., \& Hayashi, M. (2003). Levels of serum brain-derived neurotrophic factor in primates. Primates, 44(2), 167-169. https://doi.org/10.1007/s10329-002-0015-7.

Nelson, H., \& Geher, G. (2007). Mutual grooming in human dyadic relationships: an ethological perspective. Current Psychology, 26(2), 121-140. https://doi.org/10.1007/s12144-007-9009-3.

Norscia, I., \& Palagi, E. (2011). Yawn contagion and empathy in Homo sapiens. PloS one, 6(12), e28472. https://doi.org/10.1371/journal.pone.0028472.

Palagi, E., Leone, A., Mancini, G., \& Ferrari, P. F. (2009). Contagious yawning in gelada baboons as a possible expression of empathy. Proceedings of the National Academy of Sciences, 106(46), 19262-19267. https://doi.org/10.1073/pnas.0910891106.

Palagi, E., \& Mancini, G. (2011). Playing with the face: Playful facial "chattering" and signal modulation in a monkey species (Theropithecus gelada). Journal of Comparative Psychology, 125(1), 11. https://psycnet.apa.org/doi/10.1037/a0020869.

Palagi, E., \& Norscia, I. (2013). Bonobos protect and console friends and kin. PloS One, 8(11), e79290. https://doi.org/10.1371/journal.pone.0079290.

Palagi, E., Bertini, M., Annicchiarico, G., \& Cordoni, G. (2020a). Mirror replication of sexual facial expressions increases the success of sexual contacts in bonobos. Scientific reports, 10(1), 1-11. https://doi.org/10.1038/s41598-020-75790-3.

Palagi, E., Celeghin, A., Tamietto, M., Winkielman, P., \& Norscia, I. (2020b). The neuroethology of spontaneous mimicry and emotional contagion in human and non-human animals. Neuroscience \& Biobehavioral Reviews, 111, 149-165. https://doi.org/10.1016/j.neubiorev.2020.01.020. 
495 Pallante, V., Stanyon, R., \& Palagi, E. (2016). Agonistic support towards victims buffers aggression 496 in geladas (Theropithecus gelada). Behaviour, 153(9-11), 1217-1243.

497 https://doi.org/10.1163/1568539X-00003369.

498 Parr, L. A., Waller, B. M., Vick, S. J., \& Bard, K. A. (2007). Classifying chimpanzee facial 499 expressions using muscle action. Emotion, 7(1), 172. https://psycnet.apa.org/doi/10.1037/1528$500 \quad 3542.7 \cdot 1.172$.

501 Partan, S., \& Marler, P. (1999). Communication goes multimodal. Science, 283(5406), 1272-1273. 502 https://doi.org/10.1126/science.283.5406.1272.

503 Partan, S. R., \& Marler, P. (2005). Issues in the classification of multimodal communication 504 signals. The American Naturalist, 166(2), 231-245. https://doi.org/10.1086/431246.

505 Pozzi, L., Hodgson, J. A., Burrell, A. S., Sterner, K. N., Raaum, R. L., \& Disotell, T. R. (2014).

506 Primate phylogenetic relationships and divergence dates inferred from complete mitochondrial 507 genomes. Molecular phylogenetics and evolution, 75, 165-183.

$508 \quad$ https://doi.org/10.1016/j.ympev.2014.02.023.

509 Prochazkova, E., \& Kret, M. E. (2017). Connecting minds and sharing emotions through mimicry:

510 A neurocognitive model of emotional contagion. Neuroscience \& Biobehavioral Reviews, 80, 99-

511 114. https://doi.org/10.1016/j.neubiorev.2017.05.013.

512 R Core Team (2020). R: A language and environment for statistical computing. R Foundation for 513 Statistical Computing, Vienna, Austria. URL https://www.R-project.org/.

514 Ravosa, M. J., \& Savakova, D. G. (2004). Euprimate origins: the eyes have it. Journal of human 515 evolution, 46(3), 357-364. 
516 Roberts, E. K., Lu, A., Bergman, T. J., \& Beehner, J. C. (2012). A Bruce effect in wild

517 geladas. Science, 335(6073), 1222-1225. https://doi.org/10.1126/science.1213600.

518 Roberts, E. K., Lu, A., Bergman, T. J., \& Beehner, J. C. (2017). Female reproductive parameters in 519 wild geladas (Theropithecus gelada). International Journal of Primatology, 38(1), 1-20.

520 https://doi.org/10.1007/s10764-016-9939-4.

521 Saayman, G. S. (1970). The menstrual cycle and sexual behaviour in a troop of free ranging chacma 522 baboons (Papio ursinus). Folia Primatologica, 12(2), 81-110. https://doi.org/10.1159/000155283.

523 Savage-Rumbaugh, E. S., \& Wilkerson, B. J. (1978). Socio-sexual behavior in Pan paniscus and 524 Pan troglodytes: a comparative study. Journal of Human Evolution, 7(4), 327-IN6.

525 https://doi.org/10.1016/S0047-2484(78)80074-8.

526 Schino, G., Scucchi, S., Maestripieri, D., \& Turillazzi, P. G. (1988). Allogrooming as a tension527 reduction mechanism: a behavioral approach. American journal of primatology, 16(1), 43-50.

528 https://doi.org/10.1002/ajp.1350160106.

529 Schino, G., \& Sciarretta, M. (2016). Patterns of social attention in mandrills, Mandrillus 530 sphinx. International Journal of Primatology, 37(6), 752-761. https://doi.org/10.1007/s10764-016$531 \quad \underline{9936-7 .}$.

532 Sclafani, V., Norscia, I., Antonacci, D., \& Palagi, E. (2012). Scratching around mating: factors 533 affecting anxiety in wild Lemur catta. Primates, 53(3), 247-254. https://doi.org/10.1007/s10329$534 \quad \underline{012-0294-6 .}$

535 Slob, A. K., \& Nieuwenhuijsen, K. (1980). Heterosexual interactions of pairs of laboratory-housed 536 stumptail macaques (Macaca arctoides) under continuous observation with closed-circuit video 537 recording. International Journal of Primatology, 1(1), 63-80. https://doi.org/10.1007/BF02692258. 
538 Smith, J. M., \& Maynard-Smith, J. (1978). The evolution of sex (Vol. 4). Cambridge: Cambridge

539 University Press. https://doi.org/10.1017/S0016672300018693.

540 Tomasello, M., Hare, B., Lehmann, H., \& Call, J. (2007). Reliance on head versus eyes in the gaze

541 following of great apes and human infants: the cooperative eye hypothesis. Journal of human

542 evolution, 52(3), 314-320. https://doi.org/10.1016/j.jhevol.2006.10.001.

543 Tutin, C. E., \& McGinnis, P. R. (1981). Chimpanzee reproduction in the wild. Reproductive biology

544 of the great apes: Comparative and biomedical perspectives, 239-264.

545 Video Lan, (2020). VLC media player. https://www.videolan.org/vlc/index.html

546 Waller, B. M., \& Micheletta, J. (2013). Facial expression in nonhuman animals. Emotion

547 Review, 5(1), 54-59. https://doi.org/10.1177\%2F1754073912451503.

548 Wallis, S. J. (1983). Sexual behavior and reproduction of Cercocebus albigena johnstonii in Kibale

549 forest, Western Uganda. International journal of primatology, 4(2), 153-166.

550 https://doi.org/10.1007/BF02743755.

551 Wilke, C. O. (2018). Ggridges: Ridgeline plots in'ggplot2'. R package version 0.5, 1.

552 Wolfe, L. D. (1984). Female rank and reproductive success among Arashiyama B Japanese

553 macaques (Macaca fuscata). International Journal of Primatology, 5(2), 133-143.

554 https://doi.org/10.1007/BF02735737.

555 Wrangham, R. W. (1993). The evolution of sexuality in chimpanzees and bonobos. Human

556 Nature, 4(1), 47-79. https://doi.org/10.1007/BF02734089.

557 Zumpe, D., \& Michael, R. P. (1968). The clutching reaction and orgasm in the female rhesus

558 monkey (Macaca mulatta). Journal of Endocrinology, 40(1), 117-123.

559 https://doi.org/10.1677/joe.0.0400117. 
561 Table 1. Results of the GLMM showing which variables affected the occurrence of female look-at

562 during copulations.

\begin{tabular}{|c|c|c|c|c|c|}
\hline Fixed Effects & Estimate & SE & $d f$ & $z$ & $\boldsymbol{P}$ \\
\hline (Intercept) & -2.199 & 0.693 & $\overline{\mathrm{a}}$ & -3.187 & $\bar{a}$ \\
\hline Male look-at (Presence) $)^{b, c}$ & 2.285 & 0.475 & 1 & 4.837 & 0.000 \\
\hline Male copulation call (Presence) $)^{b, c}$ & -0.174 & 0.622 & 1 & -0.384 & 0.782 \\
\hline Female status (oestrus) ${ }^{\mathrm{b}, \mathrm{c}}$ & 0.649 & 0.446 & 1 & 1.466 & 0.141 \\
\hline
\end{tabular}

aNot shown as not having a meaningful interpretation.

bEstimate \pm SE refer to the difference of the response between the reported level of this categorical predictor and the reference category of the same predictor.

cThese predictors were dummy coded, with the "Male look-at (Absence)", "Male copulation call (Absence)", and "Female status (non oestrus)" being the reference categories.

Table 2. Results of the LMM showing the effect of EEC and male look-at on the copula duration.

\begin{tabular}{lrrrrr}
\hline Fixed Effects & Estimate & SE & $\boldsymbol{d f}$ & $\boldsymbol{t}$ & $\boldsymbol{P}$ \\
\hline (Intercept) & 2.212 & 0.030 & $\mathrm{a}$ & 74.022 & $\mathrm{a}$ \\
Eye-to-eye Contact (Presence) $)^{\mathrm{b}, \mathrm{c}}$ & 0.230 & 0.085 & 1 & 2.700 & $\mathbf{0 . 0 0 7}$ \\
Male look-at (Presence) ( $^{\mathrm{b}}$ & 0.038 & 0.105 & 1 & 0.363 & 0.722 \\
\hline
\end{tabular}

aNot shown as not having a meaningful interpretation.

bEstimate $\pm S E$ refer to the difference of the response between the reported level of this categorical predictor and the reference category of the same predictor.

cThese predictors were dummy coded, with the "Eye-to-eye Contact (Absence)" and "Male look-at (Absence)" being the reference category.

Table 3. Results of the GLMM showing which variables influenced the occurrence of post-copulation grooming.

\begin{tabular}{lrrrrr}
\hline Fixed Effects & Estimate & SE & $\boldsymbol{d f}$ & $\boldsymbol{z}$ & $\boldsymbol{P}$ \\
\hline (Intercept) $_{\text {Eye-to-eye Contact (Presence) }}^{\mathrm{b}, \mathrm{c}}$ & -1.084 & 0.554 & $\mathrm{a}$ & -1.956 & $\mathrm{a}$ \\
Copula duration $_{\text {Male post-copulation call seq. (Presence) }}^{\mathrm{b}, \mathrm{c}}$ & 1.062 & 0.498 & 1 & 2.134 & $\mathbf{0 . 0 2 8}$ \\
( & 0.06 & 0.038 & 1 & 1.577 & 0.102 \\
\hline
\end{tabular}

aNot shown as not having a meaningful interpretation.

$b$ Estimate $\pm S E$ refer to the difference of the response between the reported level of this categorical predictor and the reference category of the same predictor.

cThese predictors were dummy coded, with the "Eye-to-eye Contact (Absence)" and "Male post-copulation call seq. (Absence)" being the reference categories. 

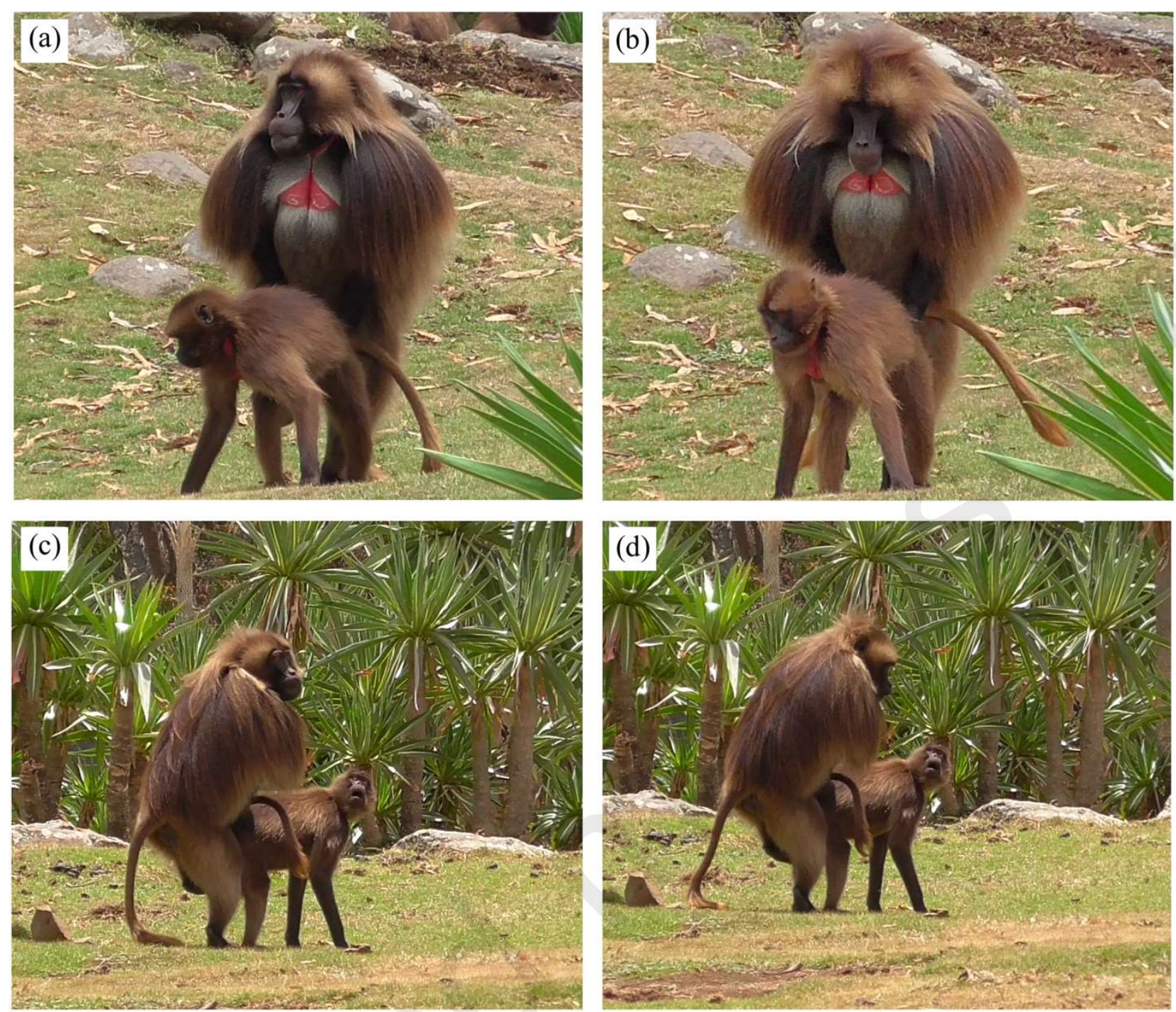

584 Figure 1. [2-column fitting image] Pictures showing the four gaze conditions. (a): no-look condition;

585 (b): male look-at condition; (c): female look-at condition; (d): EEC condition. 

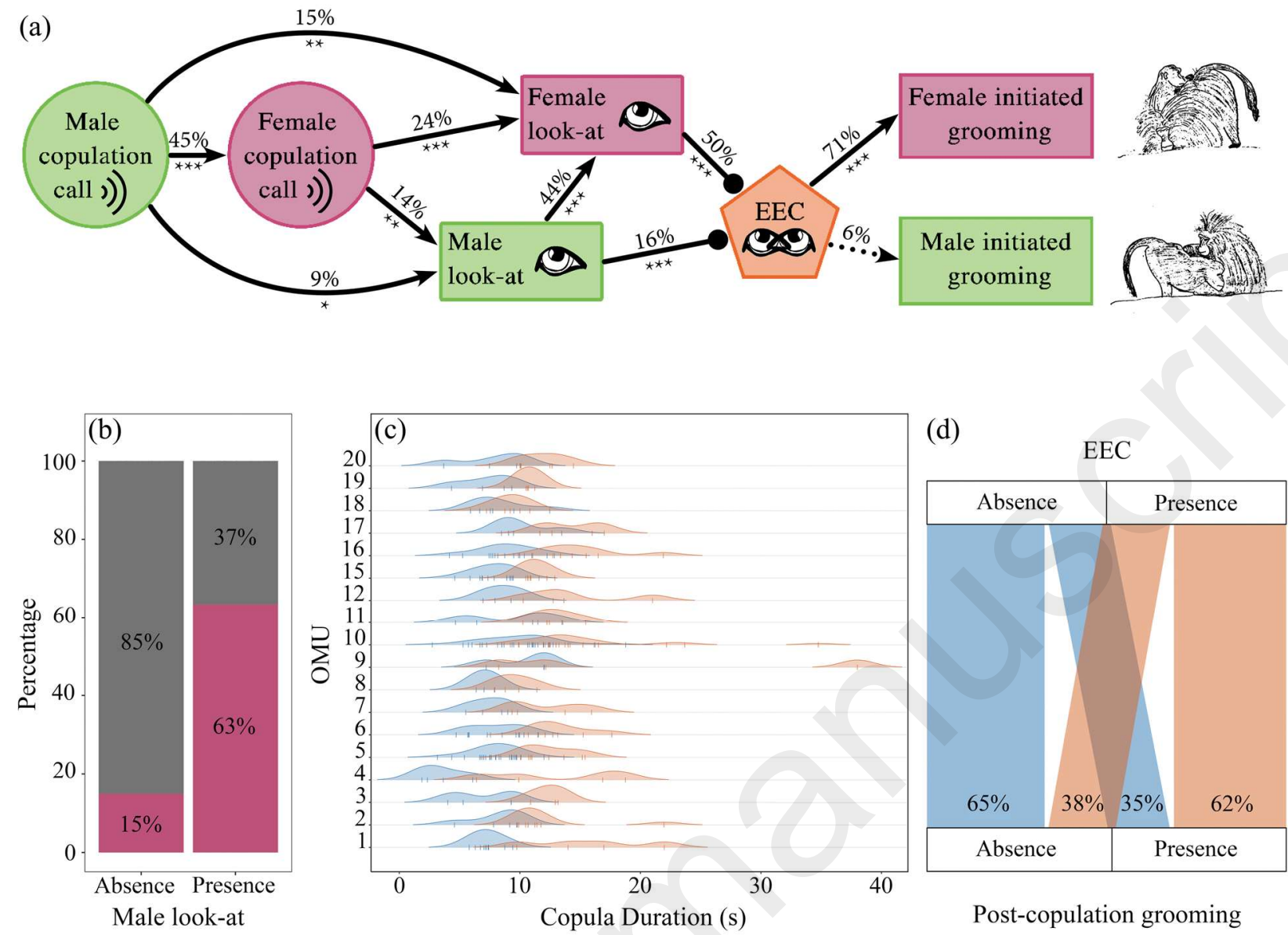

(d)

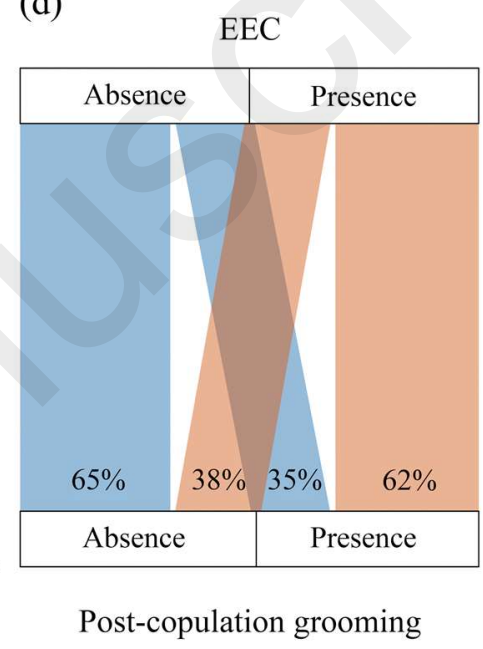

Figure 2. [2-column fitting image] (a): Flow diagram representing the transitions and the percentage of occurrence between each behaviour/vocalization and the proceeding one. Asterisks indicate significance values $(P \leq 0.001=* * * ; P<0.01=* * ; P<0.05=*)$. Round arrowheads indicate that previous behaviours can be part of the following behaviour. Dashed line indicates the non-significant transition between EEC and Male initiated grooming $(P=0.129)$. (b): Percentage of the presence of

592 Female look-at in relation with Male look-at occurrence. Dark-grey bars indicate the absence of 593 Female look-at; pink bars indicate the presence of Female look-at. (c): Raincloud ridge plot, drawn 594 with the R package "ggridges" (Wilke, 2018), showing the copula duration (s) when EEC was present 595 (orange density curves) and when it was absent (blue density curves) in the 18 OMUs studied. 596 Individual observations are presented under the density curves with pipe symbols. (d): Alluvial plot 597 (R package "ggalluvial"; Brunson \& Read, 2020) showing the percentage of presence of post- 
598 copulation grooming in the presence of EEC during copulation (orange bars) and absence of EEC 599 (blue bars) during copulation. 